\title{
Cellular Changes and Effect on DNA Integrity of the Epididymal Cells of Swiss Albino Mice Post Exposure to High Dose of Cyclophosphamide: A Histological and TUNEL Assay Study
}

\author{
Supriya ${ }^{1}$, Sneha G Kalthur ${ }^{2}$, Guruprasad Kalthur ${ }^{3}$, Guruprasad Nayak ${ }^{4}$, \\ Sandhya Kumari ${ }^{5}$ \\ ${ }^{1}$ Assistant Professor, Anatomy Department, Rajarajeswari Medical College and Hospital, \\ Bengaluru- 560074, Karnataka \\ ${ }^{2}$ Professor, Anatomy Department, Kasturba Medical College, Manipal- 576104, Karnataka \\ ${ }^{3}$ Professor, ${ }^{4,5}$ Postgraduates, Department of Clinical Embryology, Kasturba Hospital, Manipal-576 104, \\ Karnataka \\ Corresponding Author: Supriya
}

DOI: https://doi.org/10.52403/ijshr.20220111

\begin{abstract}
Background: Many studies done in past literature focuses on gonadal toxicity of Cyclophosphamide, but very less studies are done on the epididymis post exposure to this drug. Hence a sincere attempt is made in present study to look into the cellular changes in the epididymis through histology and TUNEL Assay.
\end{abstract}

Subjects \& Methods: Healthy male Swiss albino adult mice, were obtained from Central Animal Research Facility, Manipal were used for the study.

The adult as well as prepubertal male mice were divided into control and test groups. In test group, the mice were injected with Cyclophosphamide at variable doses. From each group certain no. of mice was sacrificed on different days. A control group was kept for each interval. The epididymal tissue was then extracted and used in histological and Tunnel Assay study.

Results: Even though there was no significant change in the number of basal cells, the apical cells decreased marginally at higher doses of CP. A TUNEL assay was performed in the epididymal sections to understand its effect on the DNA integrity. Up to $100 \mathrm{mg} / \mathrm{kg}, \mathrm{CP}$ did not induce any significant increase in the TUNEL positive tubules. However, at $200 \mathrm{mg} / \mathrm{kg}$ dose and above, there was an increase in the number of tubules with TUNEL positive cells indicating its DNA damaging effect. However, this increase was statistically not significant

Conclusion: The present study highlights the need for looking into the cellular damage of the cells after exposure to one of the commonly used anticancer drug- cyclophosphamide.

Keywords: Epididymal Histology, Tunnel Assay, Cyclophosphamide, Swiss Albino mice.

\section{INTRODUCTION}

Epididymis is an accessory male reproductive organ which is recognized as a channel that transports, concentrates and stores the spermatozoa. It is known that the spermatozoa leaving the testis are immovable, immature and unable to fertilize an oocyte and that under androgen control; the epididymal epithelium secretes proteins within the intraluminal compartment that create a very complex environment surrounding the spermatozoa. This luminal compartment stores the spermatozoa until ejaculation and specifically prepares the sperm for fertilization by providing the essentials in terms of temperature, oxygen tension, $\mathrm{pH}$ and an available energy substrate (1). 
Several descriptive anatomical and histological studies of the epididymis appeared at the beginning of the twentieth century. Many authors hypothesized that the epididymal secretions played a role in the maintenance of sperm vitality, sperm motility and the capacity to become fertile (2). Relatively little research was done on the excurrent duct system during the ensuing three decades. However, in 1967, Orgebin demonstrated that the key event in sperm maturation was not the passage of time but the exposure of the sperm to the luminal environment of the epididymis $(3,4)$.

Post chemotherapy studies revealed that higher doses of Cyclophosphamide caused significant reduction in epididymal weight $(5,6,7)$. The motility of cauda epididymal sperm decreased with increasing concentrations of cyclophosphamide and in addition, the concentration of mature sperm declined significantly when compared to the control. $\quad(5,6) . \quad$ Histopathological examinations of slides revealed a number of time-dependent, drug-induced changes in the histology of epididymis. The changes were however apparent like an increase in relative number and a change in distribution of halo cells in the caput epididymis, an increase in number and size of clear cells in the caput or cauda epididymis. At the electron microscopic level, there was dose dependent, two to three fold increase in the number of spermatozoa with abnormal flagellar midpieces in the lumen of both caput and cauda epididymis. (8). However, there is lack of evidence about the cellular damage to the epididymal epithelium which is significantly affecting the luminal atmosphere.

With the advancement in the field of oncology and increase in treatment techniques there is improvement in the survival rates of both adult and childhood cancers. The impact of cancer treatments on the quality of life especially fertility is greater than generally perceived. The present study is an approach to understand the epididymal changes after cyclophosphamide treatment using Swiss albino mice as experimental model.

\section{MATERIALS \& METHODS}

The present study was conducted on Male Swiss Albino (Mus musculus) mice, obtained from Central Animal Research Facility, Manipal. The exclusion criteria were included that the subject mice involved in the study did not suffer from any premorbid illness from past. 43 of adult mice aged $6-8$ weeks and 12 were prepubertal mice aged 2 weeks were considered. The mice were maintained in healthy environment inside polypropylene cages which was well ventilated. They were fed with paddy husk and fresh water as per requirement. The consent and approval was taken prior to the study from the Institutional Animal Ethics Committee, Manipal University, Manipal (IAEC Ref No $-79 / 2013)$.

The adult male mice $(n=43)$ were segregated into two groups; control $(n=7)$ and test $(n=36)$. In the test subjects, Cyclophosphamide (CP) was injected at increasing dosage of 50,100, 200 and 250 $\mathrm{mg} / \mathrm{kg}$ body weight. From each group, 3-4 mice were sacrificed on day 7, 28 and 42. A parallel control group was kept for each of the treatment intervals. Similarly, the prepubertal mice $(n=12)$ were divided into two groups; control $(n=3)$ and test $(n=9)$. Similarly, prepubertal test subjects were injected with 50,100 and $200 \mathrm{mg} / \mathrm{kg}$ body weight of CP. After a gap of 7 days, 3 mice from each of group were sacrificed to study the histology.

The control animals were injected Phosphate Buffered Saline (PBS) solution. The mice of test groups were injected with freshly prepared Cyclophosphamide solution which was purchased from SIGMA ALDRICH (C0768, St. Louis, MO 63103, USA) by dissolving it in PBS Solution. The solution prepared was injected intraperitoneally as per their body weight. The treated mice were kept under keen observation to look for any changes in hair loss, body weight changes or death. 


\section{Collection of tissue}

Mice was sacrificed by cervical dislocation and used in the present study. Dissection of the mice was referred as per the guidelines given in "The Laboratory Mouse-Handbook of experimental animals" by Hans Hedrich (2004). Briefly, the mouse was pinned to wax board in supine position. A midline incision was given on the abdominal skin, which was extended laterally towards the knee in the lower $1 / 3^{\text {rd }}$ of abdomen. The overall skin incision finally appeared like inverted Y. After skin retraction, the peritoneum was cut in similar manner and was pinned to the wax board. The intra-abdominal and pelvic organs are well exposed. Once gonads were identified, they were separated and cleared off from the adherent connective tissue, excised and were placed in PBS Solution. The epididymis was gently cleared from the testis and was taken for fixation in modified Bouin's solution $(0.2 \%$ picric acid $/ 2 \%(\mathrm{v} / \mathrm{v})$ formaldehyde in PBS) and then transferred to $70 \%$ alcohol for histological examination where the stained sections were studied under Olympus Research Microscope.

\section{TUNEL Assay}

The principle of TUNEL assay relies on terminal deoxynucleotidyl transferase (TdT)- mediated addition of a modified dUTP (X-dUTP) to 3'-OH ends of DNA fragments that are generated as a result of apoptosis induction. The tissue sections were fixed on the slides using poly-L-lysine coating and subjected to permeabilization prior to labeling. The assay thus serves as a parameter for the percentage of apoptotic cells within the analyzed cell population. The slides for Tunnel Assay were Counterstained with DAPI $(4 \mu \mathrm{g} / \mathrm{ml})$ \& mount in DAKO for analysis.

Statistical Analysis: The data was represented as mean \pm standard error and was calculated using Microsoft Excel and Origin 6.0 software (Microcal ${ }^{\mathrm{TM}}$ Origin $\AA$, Version: 6.0, Northampton, MA 01060, USA). The statistical significance of the data was analyzed using one way ANOVA test using GraphPad InStat Software (Version: 3.06, 32 bit for Windows). ' $p$ ' value $<0.05$ was considered as statistically significant.

\section{RESULT}

\section{Effect of CP administration on epididymis}

Epididymis plays a significant role in maturation of spermatozoa which is very essential to gain fertilizing ability. Mainly the cellular change in the caput region was analyzed. The epididymis is composed of three major cell types- principal cells, apical cells and basal cells.

\section{Pre-pubertal epididymis}

Effect on principal cells: The epididymis of control mice in the caput region had $37.9 \pm 3.11$ principal cells which was significantly higher in mice exposed to $50 \mathrm{mg} / \mathrm{kg} \mathrm{CP}$ ( $\mathrm{p}<0.05)$. But at higher doses even though the number of cells were higher than the control $(49.23 \pm 3.23$ and $50.26 \pm$ 4.81 in 100 and $200 \mathrm{mg} / \mathrm{kg}$ dose respectively) the increase was not significant compared to control (Figure 1).

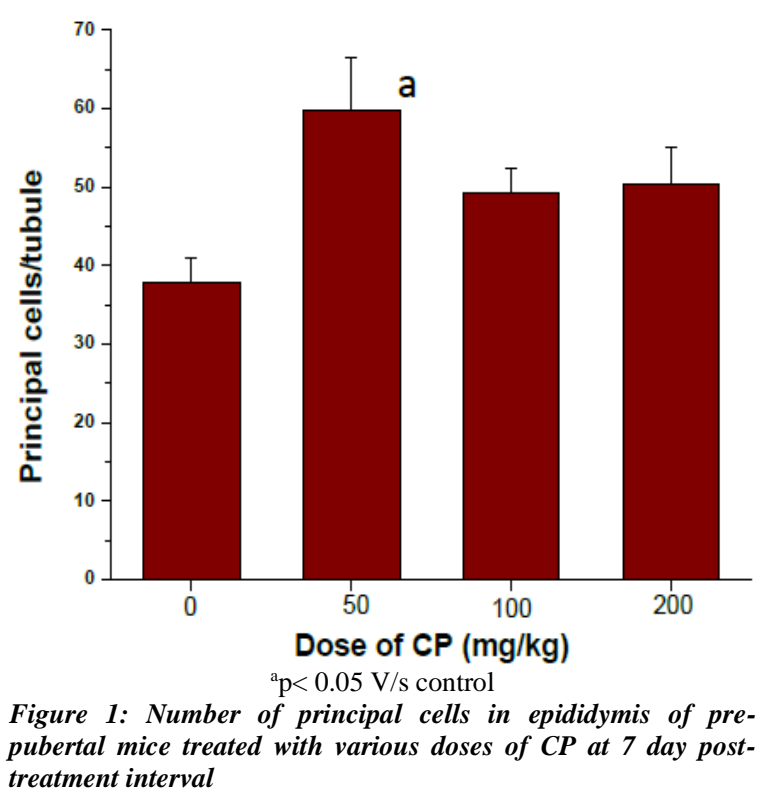

From Figure 2 it is clear that $\mathrm{CP}$ did not have any significant effect on either apical cells or basal cells. However, a marginally higher number of basal cells were observed in $\mathrm{CP}$ treated mice. 

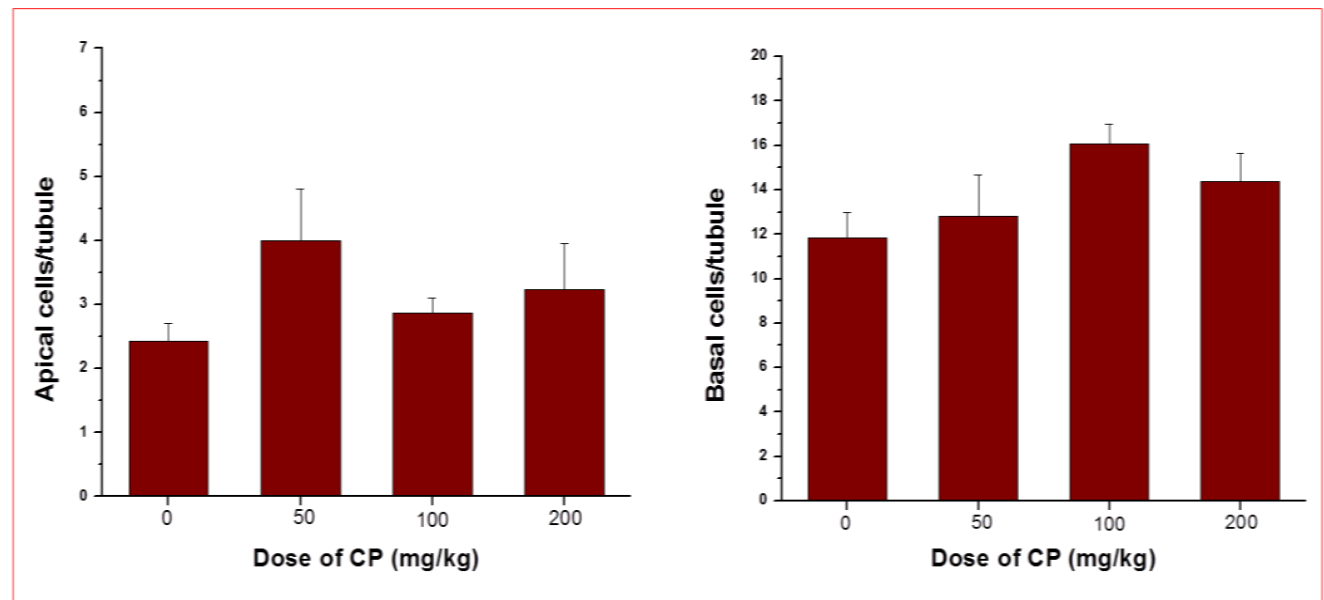

Figure 2: Number of apical and basal cells in epididymis of pre-pubertal mice treated with various doses of CP at 7 day post-treatment interval

\section{Adult mice}

The effect of $\mathrm{CP}$ on epididymal histology was assessed at 7, 28 and 42 days after treatment. The Figure 3, 4 and 5 depicts the changes in the epididymal cellularity with respect to principal, apical and basal cell number. The epididymis from the control mice had $53.17 \pm 1.37$ principal cells which did not differ much with increase in time (Figure 3). However, in CP treated mice, there was a significant decrease in the principal cells at 7 day post treatment interval, especially in mice treated with 200 and $250 \mathrm{mg} / \mathrm{kg}$ of CP. At later intervals there was no significant difference in the number of these cells.

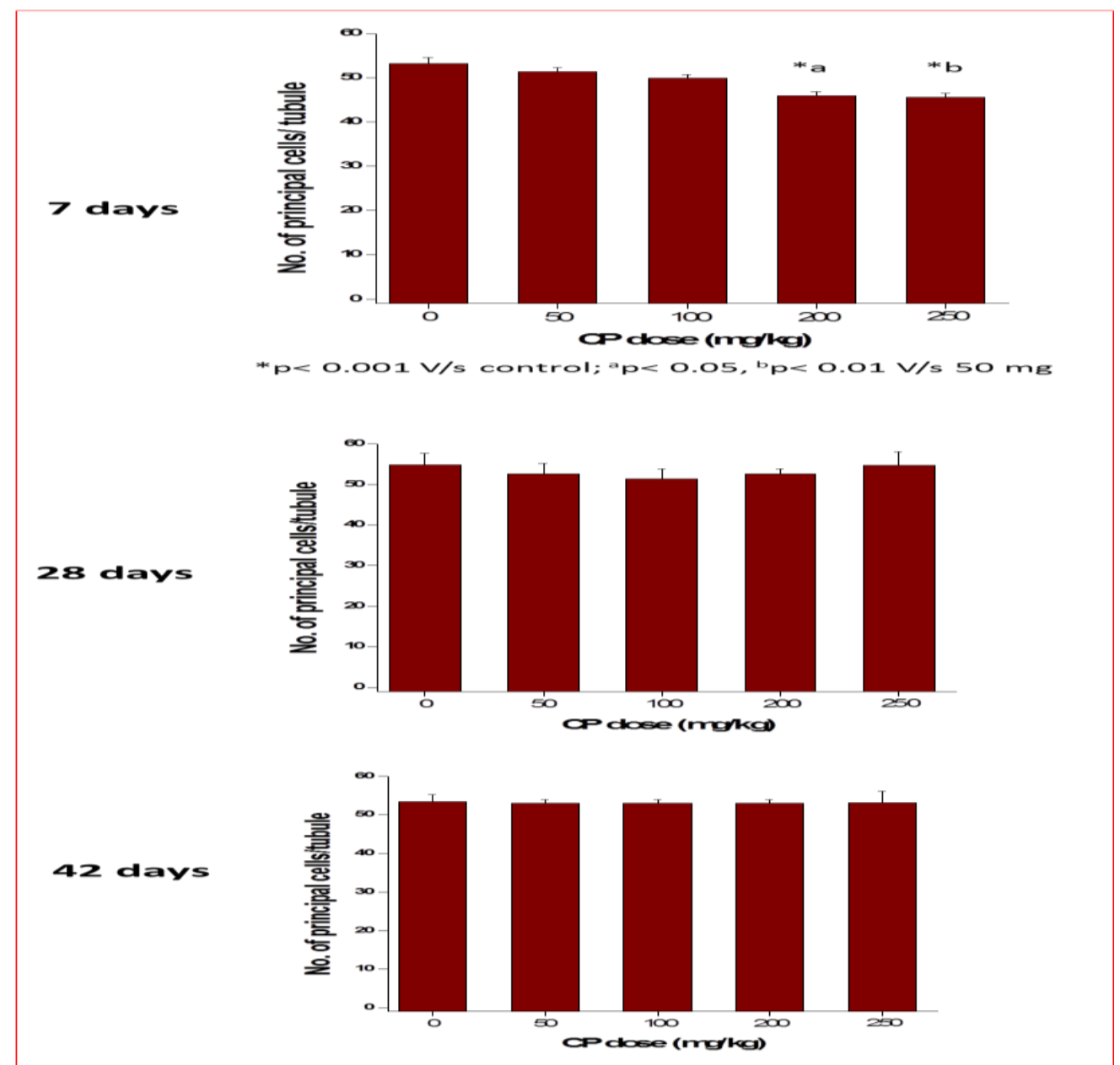

Figure 3: Number of principal cells in epididymis of adult mice treated with various doses of CP at different post-treatment interval 
Supriya et.al. Cellular changes and effect on DNA integrity of the epididymal cells of Swiss albino mice post exposure to high dose of cyclophosphamide: a histological and TUNEL assay study

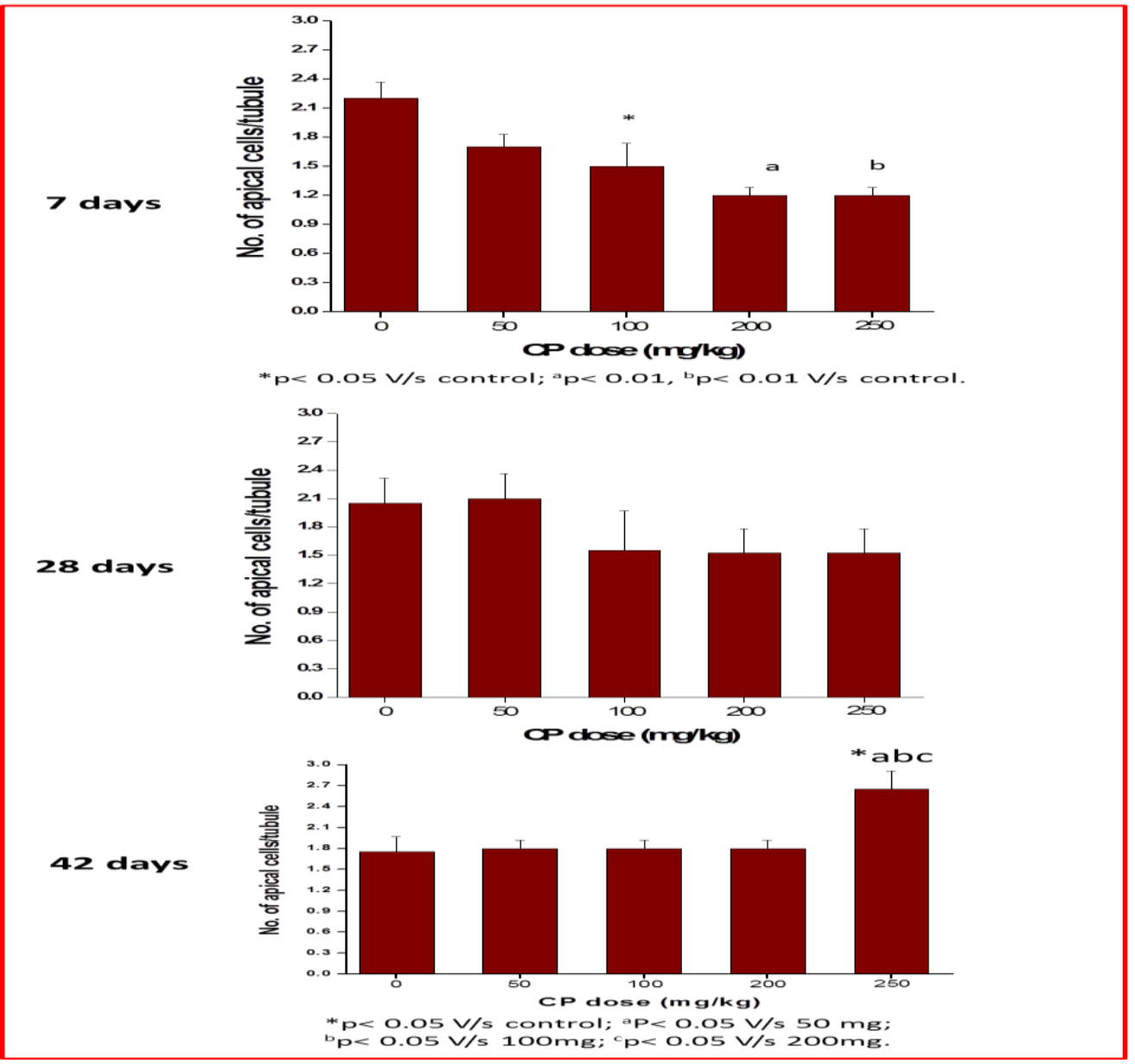

Figure 4: Number of apical cells in epididymis of adult mice treated with various doses of CP at different post-treatment interval

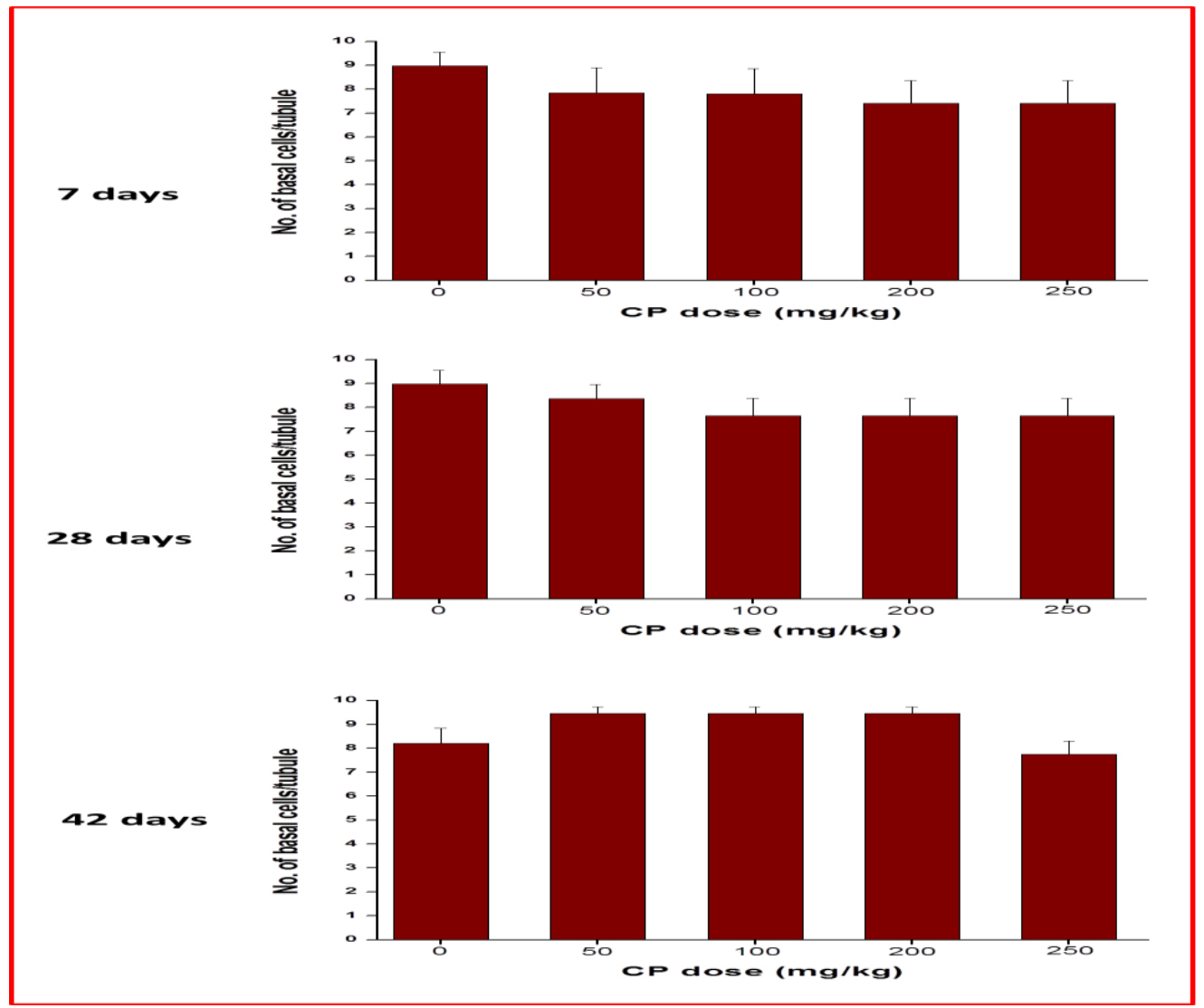

Figure 5: Number of basal cells in epididymis of adult mice treated with various doses of $\mathrm{CP}$ at different post-treatment interval 

exposure to high dose of cyclophosphamide: a histological and TUNEL assay study

Further, there was decrease in the apical cell number at 7 day post treatment interval in mice treated with 100,200 and $250 \mathrm{mg} / \mathrm{kg} \mathrm{CP}(\mathrm{p}<0.05, \mathrm{p}<0.01$ and $\mathrm{p}<$ 0.01 respectively). At 28 day interval though the apical cells were lower than the control group, especially in the higher doses, it was statistically not significant. Surprisingly, on day 42 , there was significant increase in the apical cells of mice treated with $250 \mathrm{mg} / \mathrm{kg}$ of $\mathrm{CP}$ ( $\mathrm{p}<$
0.05) compared to control and the other doses of $\mathrm{CP}(\mathrm{p}<0.0 .5)$.

Similarly, the control epididymis had $8.97 \pm 0.57$ basal cells which did not change with increase in the time. In all $\mathrm{CP}$ treated group the number was nonsignificantly lower than control at 7 and 28 days post treatment interval. While on day 42 , mice treated with up to $200 \mathrm{mg} / \mathrm{kg}$ of $\mathrm{CP}$, there was a marginal non-significant increase.

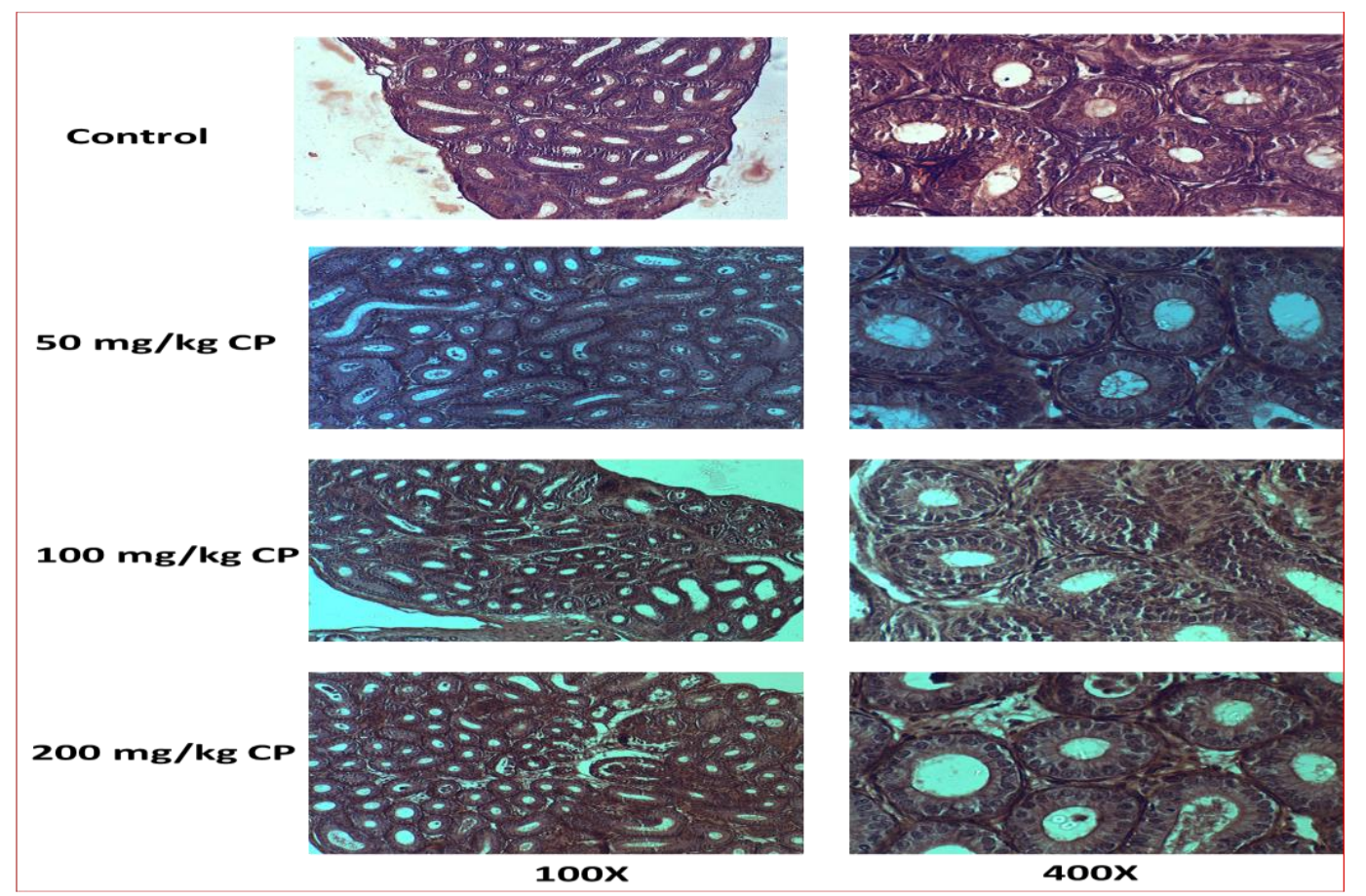

Image 1: Representative images of epididymis of pre-pubertal mice exposed to various doses of CP at 7 day post-treatment interval

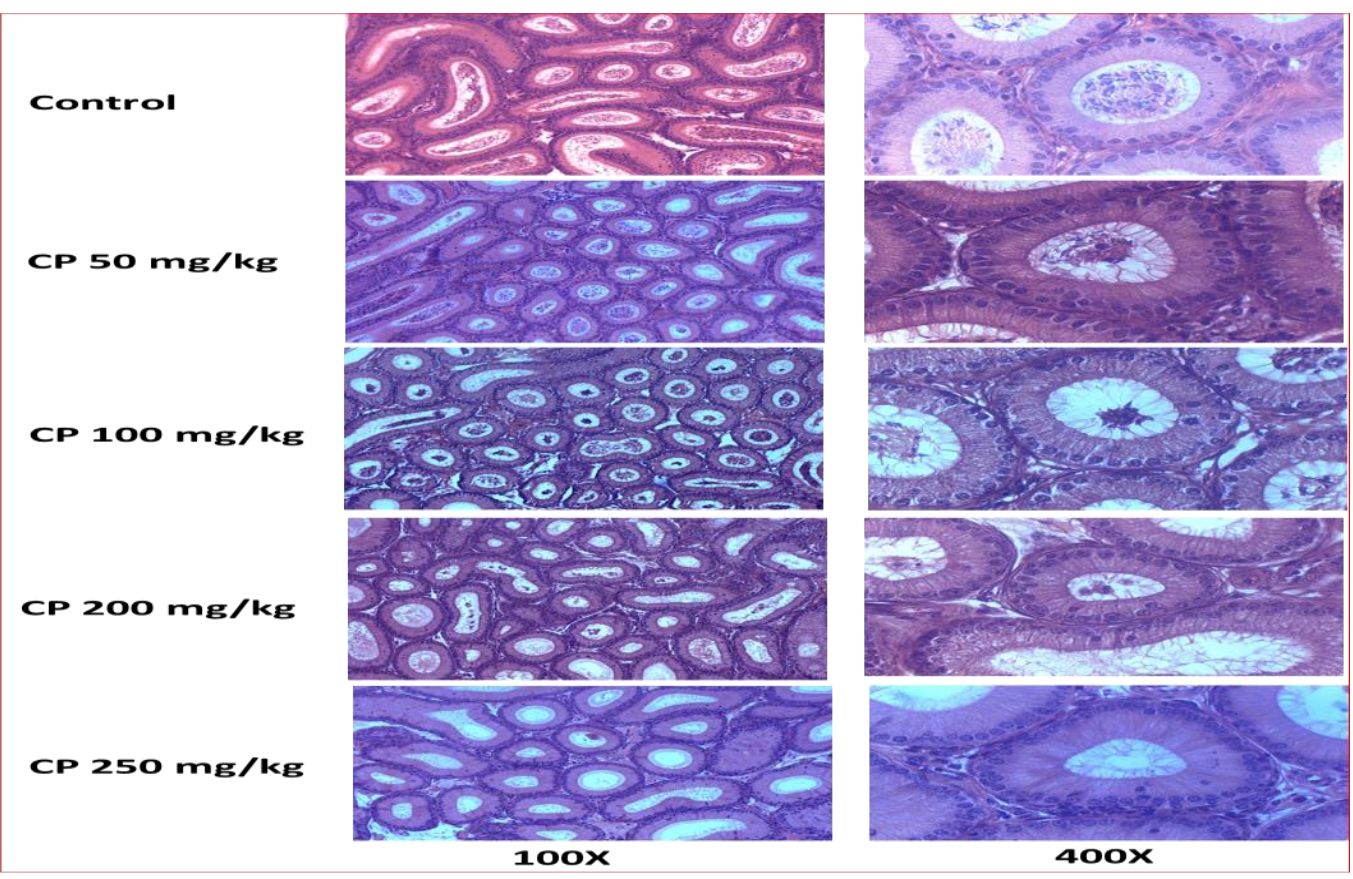

Image 2: Representative images of epididymis of adult mice treated with various doses of CP at 7 day post-treatment interval 
Supriya et.al. Cellular changes and effect on DNA integrity of the epididymal cells of Swiss albino mice post exposure to high dose of cyclophosphamide: a histological and TUNEL assay study

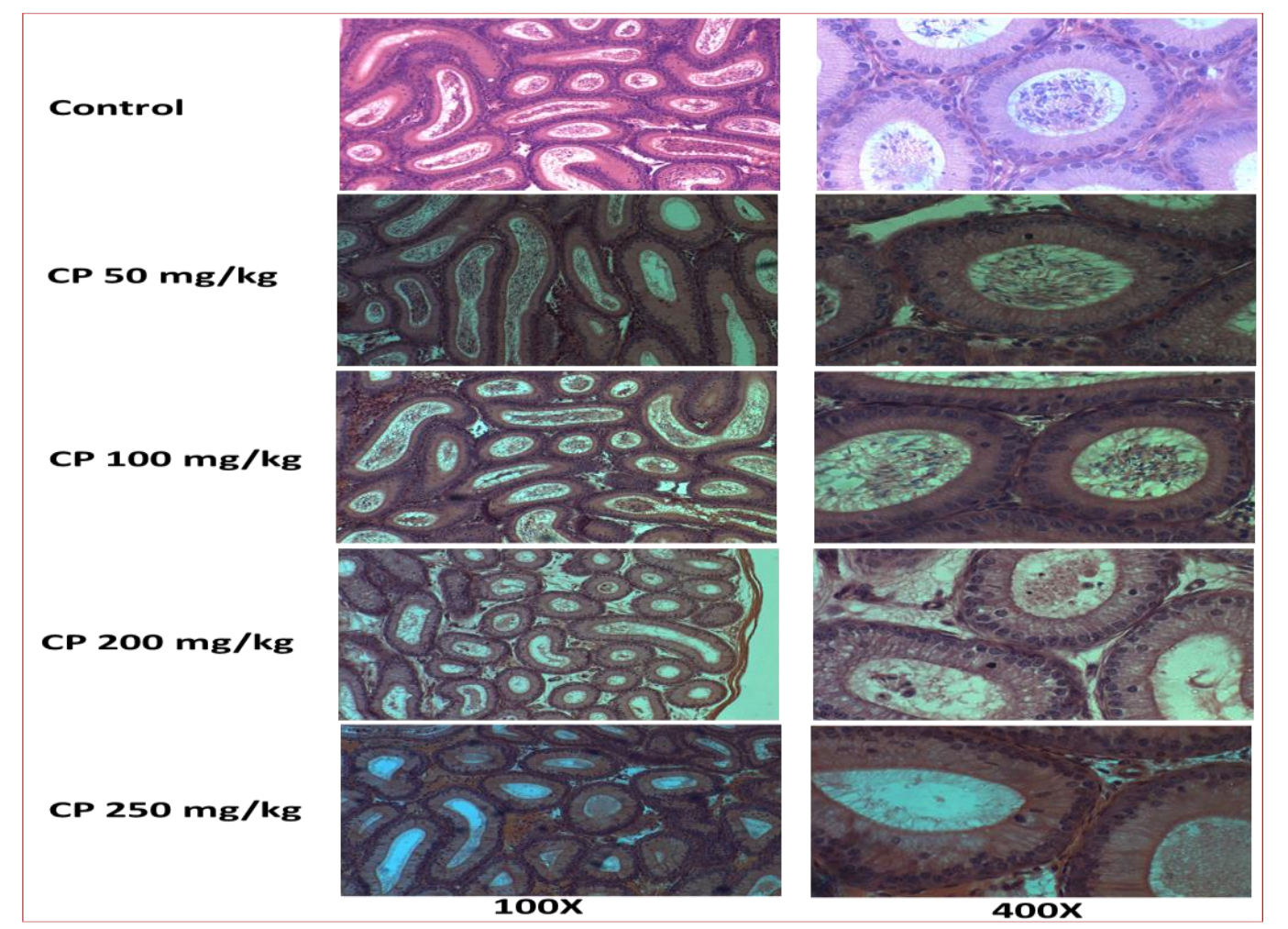

Image 3: Representative images of epididymis of adult mice treated with various doses of CP at 28 day post-treatment interval

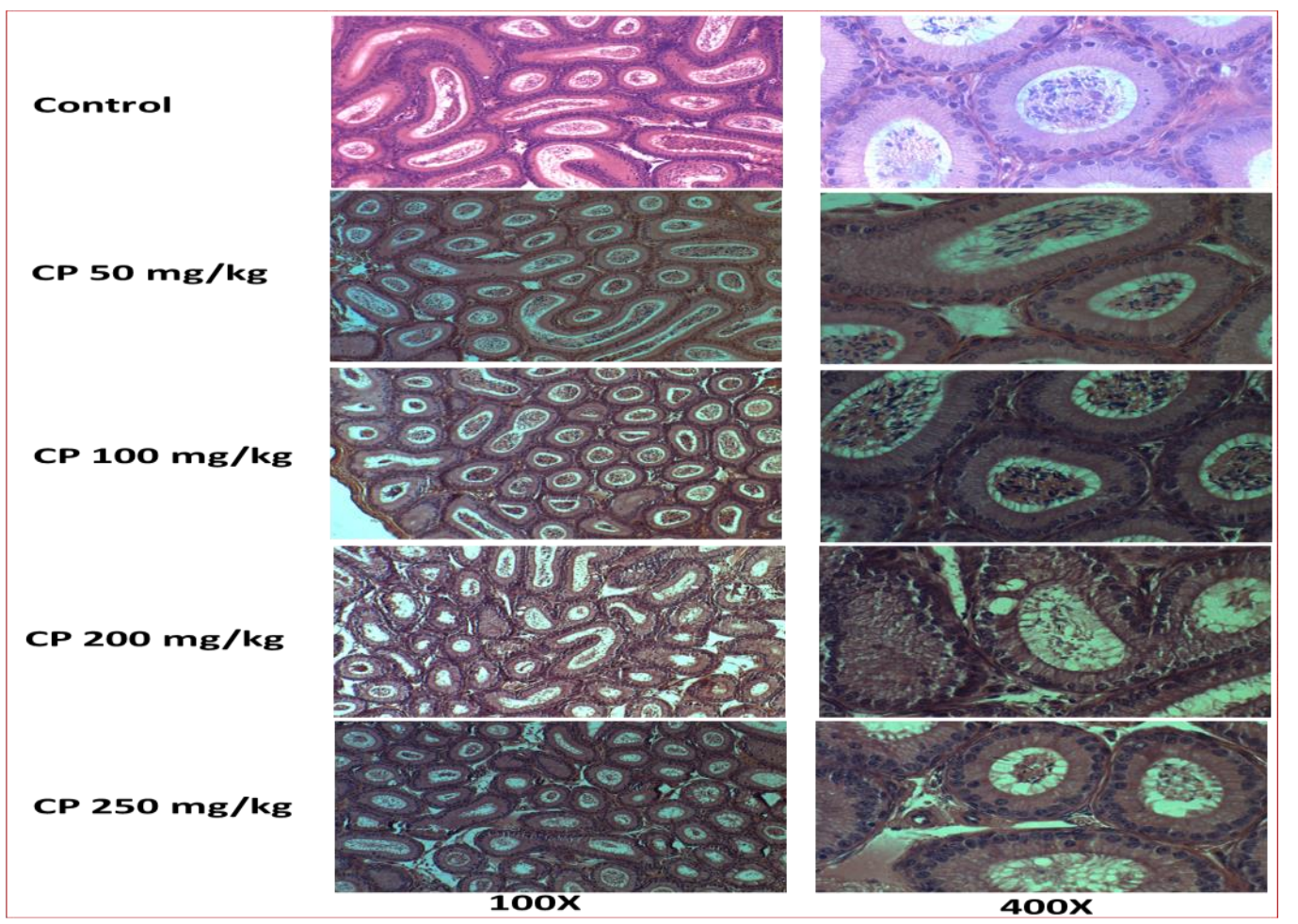

Image 4: Representative images of epididymis of adult mice treated with various doses of CP at 42 day post-treatment interval

Effect on the DNA integrity of epididymal cells

Since the $\mathrm{CP}$ administration resulted in changes in the cellularity of the adult epididymis, especially at the highest dose used in the present study $(250 \mathrm{mg} / \mathrm{kg})$,
TUNEL assay was performed in the epididymal sections to understand its effect on the DNA integrity. The number of TUNEL positive cells per tubule was assessed. 


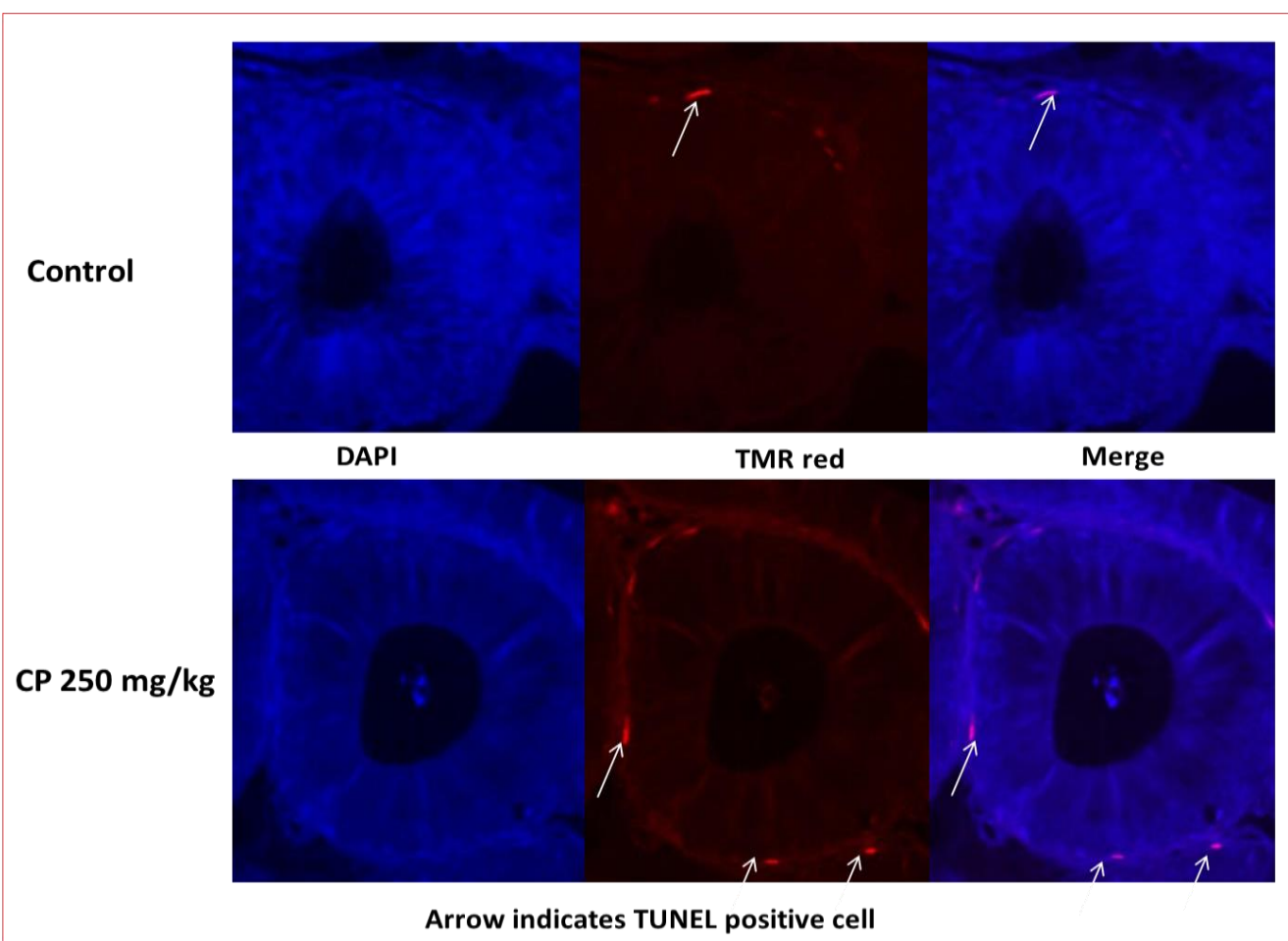

Image 5: DNA integrity in epididymal cells of adult mice exposed to $250 \mathrm{mg} / \mathrm{kg}$ of CP. The nucleus was counterstained with fluorescent dye DAPI (400X).

In the control group, $2.02 \pm 1.01$ tubules were having DNA damage expressed as TUNEL positive tubules. Up to $100 \mathrm{mg} / \mathrm{kg}, \quad \mathrm{CP}$ did not induce any significant increase in the TUNEL positive tubules. However, at $200 \mathrm{mg} / \mathrm{kg}$ dose and above, there was an increase in the number of tubules with TUNEL positive cells indicating its DNA damaging effect. However, this increase was statistically not significant.

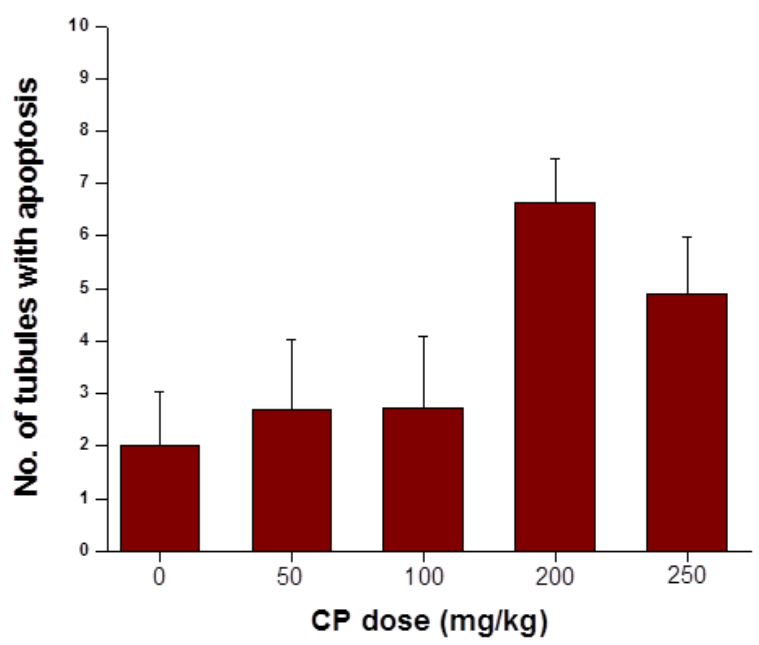

Figure 6: DNA damage in the epididymis of adult mice treated with various doses of $C P$

\section{DISCUSSION}

Epididymis plays an important role in sperm transport as well as sperm maturation. Epithelial cells lining the epididymal lumen secretes several important factors required for final maturation of spermatozoa. The histology of various cell types in adult rat epididymis has been reviewed in detail by various authors $(9,10)$, although very few study has been done on mice to understand the effect of anticancer drugs like $\mathrm{CP}$ on the histology of epididymis.

The epididymis is lined by pseudo stratified columnar epithelial cells which has specific function. Even though there are certain discrepancies about the function of these cells, the current belief is that principal cells are the most abundant and extensively studied cell type found in the epididymal epithelium. Principal cells constitute approximately $80 \%$ of the total epithelial cell population in the initial segment. The number of principal cells gradually decreases to $65 \%$ of the total epithelial cell population in the cauda epididymis (10). They are responsible for the bulk of the proteins that are secreted into 
the lumen and are directly involved in the control of luminal protein concentrations. The basal cells are the second most abundant cell type found in the epididymal epithelium, constituting $15-20 \%$ of the total epithelial cell population of the epididymis. They are triangular and flat cells and they reside in the base of the epithelium. It is suggested that these cells may have a role in the epithelial immune system and in the regulation of electrolytes. However, the exact functions of these cells are not yet clear (11). The apical cells comprise approximately $10 \%$ of the total epithelial population in the initial segment but only approximately $1 \%$ of the total epithelial population in the cauda of the epididymis. These cells are believed to regulate $\mathrm{pH}$ in the lumen through the production of enzymes of the carbonic anhydrase family (11).

The principal cells being the predominant cell type throughout the epididymis have been noted by a number of investigators $(12,13)$. The administration of $\mathrm{CP}$ caused an increase in the number of principal cells per tubule which was more predominant at the lower dose (significantly higher than control). These results are similar to that done by Trasler et al., (1988), where he found significant one to one half increase over control after 1 week of treatment. The relative percentile contribution of principal cells increased with the low dose but not with the higher dose. Even though there was no significant change in the number of basal cells, the apical cells decreased marginally at higher doses of CP.

Surprisingly, the adult epididymis had a different response to $\mathrm{CP}$ administration. The principal cells are significantly decreased at higher doses at 7 day interval. However, with increase in the recovery period after $\mathrm{CP}$ administration, the principal cells were repopulated in the epididymal compartment suggesting that the effect of CP was transient and even after exposure to very high doses of $\mathrm{CP}$, the epididymal tissue can recover histologically and probably also functionally which needs further studies. Trasler et al., (1988) noticed the abnormal distribution pattern of cells in the caput region. The cells in this region had larger size but the number did not change. Whereas, in the cauda region of epididymis, epithelial lining had increased number of epithelial cells which were larger in size.

In the scanning electron microscopy done by Hamilton, (1977) regarding the surface morphology of epididymal cells in rat, it was noted that the luminal surface of apical cells is composed of flagellar folds reminiscent of the kind found on cells actively engaged in phagocytosis. It has been suggested that the apical cells from untreated rats can take up the contents of cytoplasmic droplets shed by spermatozoa $(10,11)$. It is possible that increase in the size of the apical cells in CP treated animals is due to the increase in uptake of breakdown products of abnormal spermatozoa. However, the cause for increase in number of apical cells still remains unknown.

The lumen of epididymal tubule showed low sperm concentration when compared to control, which was similar to findings obtained by Kamarzaman et al., (2013). Added to his, he had also noted a marked decrease in the concentration of mature sperm in the epididymal lumen, when the animals were exposed to $\mathrm{CP}$ for a longer period of 32 days. The results also match with that of Kim et al., (2013), where the epididymal index (amount of sperm in the ductus epididymis) in $\mathrm{CP}$ group decreased significantly in comparison with that in the control. In addition, in high doses of $\mathrm{CP}$ treated groups the epididymal sections showed relatively larger spaces between the epididymal tubules and lumens being filled with edema fluid, these findings are similar to the findings obtained by Moshtak et al., 2012.

The TUNEL assay quantifies the incorporation of biotinylated dUTP at double strand breaks in DNA using a reaction catalyzed by template independent terminal deoxynucleotidyl transferase. The 
assay scores florescent cells with labelled DNA. TUNEL which detects apoptosis specific DNA fragmentation is said to be sensitive for both single and double stranded breaks. It also has the advantage of being relatively quick and easy to perform.

The DNA integrity in nuclei of the epididymal cells exposed to cytotoxic doses was analyzed in present study using TUNEL assay with the parallel control group. In the control group, 2.02 \pm 1.01 tubules were having DNA damage expressed as TUNEL positive tubules. However higher doses, especially at $200 \mathrm{mg} / \mathrm{kg}$ dose and above, there was an increase in the number of tubules with TUNEL positive cells indicating its DNA damaging effect.

The alkylating effect of $\mathrm{CP}$ on the DNA of epididymal epithelial cells might have resulted in elevated percentage of apoptotic cells. Oxidative stress generated by $\mathrm{CP}$ due to significant increase in testicular reactive oxygen species (ROS) level, along with a significant decrease in cellular thiol levels (5). The oxidative stress is believed to be involved in the etiology of toxicities of many xenobiotics $(15,16)$. Some of the pathological alterations like disturbed spermatogenesis, severe damage of seminiferous tubules with complete loss of the spermatogonial cells are attributed to the oxidative stress induced by increasing lipid peroxidation produced by $\mathrm{CP}$ as well as to the ability of the activated metabolites of CP (which are alkylating agents) to cause cross linking of DNA strands, interfering with normal cell division in all rapidly proliferating tissues. In addition, cyclophosphamide can disrupt the redox balance of tissues suggesting that biochemical and physiological disturbances may result from oxidative stress caused by the generation of free radicals and ROS30 and due to their high polyunsaturated fatty acid content, spermatozoa plasma membranes are highly sensitive to ROSinduced damage and lipid peroxidation (17).

There are not many studies done on the epididymal cells to check its DNA integrity in its nuclei. However, some of the studies such as Codrington et al., (2004), Sabik and Rahman., (2009) revealed an increased number of TUNEL positive male germ cells in cyclophosphamide treated group compared to control group.

\section{CONCLUSION}

Cyclophosphamide, a well known anticancer though known for its toxic effects on testis, very less studies focus on the cellular changes on Epididymis. In this present experimental study on mice model, an attempt is made to look into the cellular changes in the histology. In addition, as a special attempt is made to look into the DNA integrity of the cells lining epididymal epithelium, by recognizing the apoptotic cells through TUNNEL ASSAY study.

Acknowledgement: I wish to acknowledge the Department of Anatomy and Department of Clinical Embryology, Kasturba Medical College and Hospital, Manipal, for their support and training me during the study period.

\section{Conflict of Interest: None}

\section{Source of Funding: None}

\section{Ethical Approval: Approved}

\section{REFERENCES}

1. Kelen, L.M., Juliani, L.C., Taylor, A.C. (2014) Effects of Copaipa oil on cyclophosphamide induced teratogenesis in mice. American Journal of Plant Sciences. 5(23). 3464-3473.

2. Young, W.C. (1929) A Study of the function of the epididymis. The importance of aging process in sperm for the length of the period during which fertilizing capacity is retained by sperm isolation in the epididymis of the guinea pig. J Morphol. 48. 475-491.

3. Bedford, J.M. (1967) Experimental requirement for capacitation and observations on ultrastructural changes in rabbit spermatozoa during fertilization. $J$. Reprod. Fert. Suppl. 8. 19-26.

4. Orgebin, C.M.C. (1967) Sperm maturation in rabit epididymis. Nature. 216-816. 
5. Elangovan, N., Chiou, T.J., Tzeng, W.F., Chu, S.T. (2006) Cyclophosphamide treatment causes impairment of sperm and its fertilizing ability in mice. Toxicology. 222.60-70.

6. Kamarzaman, S., Shaban, M., Rahman, S.A. (2013) Effects on mouse spermatogenesis and DNA fragmentation following exposure to cyclophosphamide and thymoquinone. European International Journal of Science and Technology. 2(7). 119-136.

7. Rahman, S.A., Dawood, N.F. (2013) Protective effect of black seed Nigella Sativa against cyclophosphamide induced toxicity on reproductive and acrosomal function in mice. Middle-East Journal of Scientific Research 17(7). 955-964.

8. Trasler, J.M., Hermo, L., Bernard, R. (1988) Morphological changes in the testis and epididymis of rats treated with cyclophosphamide: A Quantitative approach. Biology of reproduction. 38. 463479.

9. Hamilton, D.W. (1975) Structure and function of the epithelium lining the ductuli efferent, ductus epididymis and the ductus deferens in rat. Handbook of Physiology in rats. 5. 259-301.

10. Robarie, B., Hermo, L. (1988) Efferent ducts, epididymis and vas deferens, Structure, function and their regulation. Physiology of Reproduction. 999-1080.

11. Hermo, L., Clermount, Y. (2005) Light cells within the limiting membrane of rat seminiferous tubules. American Journal of Anatomy. 145(4). 467-483.

12. Calrmount, Y., Flannery, J., (1970) Mitotic activity in the epithelium of the epididymis in young and old adult rats. Biol Reprod 3. 283-292.

13. Glover, T. D., Nicander, L. (1971) Some aspects of structure and function in the mammalian epididymis. J Reprod Fertil. 13. 39-50.

14. Moshtak, A. W., Farhood, H.F., Mostafa, F.J., Jaber, I.A., Ali, Q.M., Ameri, A., Gathwan, K.H., Al Saadi, A.F., Ewadh, M.J. (2012) The effect of Cyclophosphamide on spermatogenesis in rats. Research in Pharmac. 2(3). 15-21.

15. Premkumar, K., Pachiappan, A., Abraham, S.K., Santhiya, S.T., Gopinath, P.M., Ramesh A. (2001) Effect of Spirulina fusiformis on cyclophosphamide and mitomycin-C induced genotoxicity and oxidative stress in mice. Fitoterapia.72. 906-11.

16. Sabik, L.M.E., Rahman, S.S.A. (2009) Alpha-tocopherol and ginger are protective on Cyclophosphamide-induced gonadal toxicity in adult male albino rats. Basic and Applied Pathology. 2. 21-29

17. Codrington, A.M., Hales, B.F., Robaire, B. (2004) Spermiogenic germ cell phasespecific DNA damage following cyclophosphamide exposure. J Androl. 25. 354-62.

18. Kim, S.H., Lee, I.C., Baek, H.S., Moon, C., Kim, S.H., Kim, J.C. (2013) Protective effect of diallyl disulfide on cyclophosphamide-induced gonadal toxicity in rats. Laboratory Animal Research. 29(4). 204-211.

How to cite this article: Supriya, Kalthur SG, Kalthur $\mathrm{G}$ et.al. Cellular changes and effect on DNA integrity of the epididymal cells of Swiss albino mice post exposure to high dose of cyclophosphamide: a histological and TUNEL assay study. International Journal of Science \& Healthcare Research. 2022; 7(1): 54-64. DOI: https://doi.org/10.52403/ijshr.20220111 